\title{
LOW REPRODUCTIVE SUCCESS IN TWO SUBSPECIES OF JUNIPERUS OXYCEDRUS L.
}

\author{
Pedro L. Ortiz,' Montserrat Arista, and Salvador Talavera \\ Departamento de Biología Vegetal y Ecología, Universidad de Sevilla, Apdo. 1095, 41080 Sevilla, Spain
}

\begin{abstract}
Mature seed cone and seed production were studied in six populations of Juniperus oxycedrus (three of subspecies oxycedrus and three of subspecies macrocarpa). In both subspecies, seed cone abortion took place mainly just after the pollination period, and most of the remaining seed cones reached full size. Percentage of mature cones was significantly higher in subspecies oxycedrus than in macrocarpa. In both taxa, seed cones developed fully in the absence of filled seeds. Both the number of full-sized seeds per cone and the seed viability were low, and they were similar in both subspecies. However, seed potential was markedly higher in subsp. macrocarpa (mean 4.1 ovules/cone) than in subspecies oxycedrus (mean 2.8 ovules/cone), indicating a lower seed efficiency in subspecies macrocarpa. Results indicate that deficient pollination and site quality can be causes of low seed cone production and low seed viability in both subspecies of $J$. oxycedrus.
\end{abstract}

\section{Introduction}

One of the most common ecological problems in conifers is the reduction in viable seed crops (Colangeli and Owens 1990; Owens et al. 1990; Arista and Talavera 1996). Lack of pollination, low pollen viability, or embryo degeneration (as a consequence of selfing) have all been implicated as causes of reduced seed production (Owens et al. 1991; Arista and Talavera 1996). Among conifers, monoecy is the predominant breeding system; the presence of male and female structures in the same plant often leads to self-pollination and consequently endogamy. However, in some monoecious conifers the spatial separation of female and male structures (Kuittinen and Savolainen 1992), the temporal difference between receptivity of female cones and shedding of pollen in the same plant (dichogamy, Sarvas 1962), or a subdioecious condition (Jordano 1991; Wilson et al. 1996; Arista and Talavera 1997) reduce the rate of selfing.

One of the most effective alternatives for preventing inbreeding is dioecy; however, because male and female strobili are on separate trees, dioecy can lead to a lack of pollination. Among conifers, dioecy is a rare breeding system, with only a few genera, e.g., Juniperus and Taxus, having dioecious species. Juniperus is the second largest genus of the conifers, with ca. 75-80 taxa (Franco 1964). Juniperus oxycedrus L. is a dioecious species widely distributed in the Mediterranean region (Franco 1964). There is little information about seed crops in dioecious junipers (Houle and Babeux 1994), and no data about cone or seed production are available for J. oxycedrus. The aim of this study was to determine interpopulation and intersubspecies variations in mature seed cone and seed production in $J$. oxycedrus.

\section{Material and Methods}

Juniperus oxycedrus has two common subspecies in southwestern Spain, J. oxycedrus subspecies oxycedrus and J. oxycedrus subsp. macrocarpa (Sibth. \& Sm.) Ball, which

'Author for correspondence and reprints.

Manuscript received July 1997; revised manuscript received March 1998. grow on mountainous and on sandy coastal zones, respectively. Both subspecies of J. oxycedrus are shrubs-or sometimes small trees - that have a 2 -yr reproductive cycle. Pollination occurs in October-November in a given year, fertilization takes place in May-June of the following year, and seed cones are ripe in September-October of the second year (M. Arista et al., unpublished data). Ripe seed cones are axillary, dark red, fleshy, and globose and are bigger in subspecies macrocarpa (about $16 \mathrm{~mm}$ vs. $10 \mathrm{~mm}$ in subsp. oxycedrus).

The study was carried out from 1994 to 1996 in six populations of $J$. oxycedrus: three of subsp. oxycedrus and three of subsp. macrocarpa (table 1). During October-November, the sexual ratio (number of male plants/number of female plants) was determined in each population. Production of seed cones was studied using five to six randomly selected branches per plant on ca. 10 individuals in each population. These branches were marked and their seed cone production, the number of seed cones in development after pollination, and the number of seed cones that ripened were counted. Mature seed cones were collected in October just before dispersion and the total number of full-sized seeds per cone was determined. Flat seeds were not counted. Each full-sized seed (hereafter, called simply "seed") was cut lengthwise to determine embryo presence (seeds with embryo are denoted as "filled seeds," and those without it are denoted as "empty seeds"). These data were used to estimate the percentage of seed viability per plant and per population.

Data were analyzed using one-factor factorial design analyses of variance (ANOVA). When significant differences between populations were presented $(P<0.05)$, these were located with Tukey tests. Prior to any statistical analyses, variables were checked for normality and transformed as necessary. Deviation from unity for the sex ratio of the six populations was verified with the $G$ test (Sokal and Rohlf 1981).

\section{Results}

\section{Interplant and Interpopulation Variation}

Cone abortion was absent or rare during postpollination developmental in all populations. Percentage of mature cones was markedly variable between plants within each population and between populations (table 2). The Punta Umbría population had the lowest percentage of cone maturation $(19.23 \%)$ and that of Puerto Saucillo had the highest $(43.9 \%$; table 2$)$.

No external differences were observed between 
Table 1 Characteristics of the Six Studied Populations of Juniperus oxycedrus in Southern Spain

\begin{tabular}{|c|c|c|c|c|c|}
\hline Subspecies and site & Province & Protection level & Elevation & Soils & Situation \\
\hline \multicolumn{6}{|l|}{ macrocarpa: } \\
\hline Punta Umbría ........ & Huelva & Nature site (Enebrales de Punta Umbría) & $0 \mathrm{~m}$ & Coastal sandy & Dunes beside sea \\
\hline Pinar de Barbate .... & Cádiz & Nature park (Acantilado y Pinar de Barbate) & $100 \mathrm{~m}$ & Coastal sandy & Plain on sea cliff \\
\hline Punta Paloma ......... & Cádiz & Unprotected & $0 \mathrm{~m}$ & Coastal sandy & Dunes beside sea \\
\hline \multicolumn{6}{|l|}{ oxycedrus: } \\
\hline Puerto Saucillo ....... & Málaga & Nature park (Sierra de las Nieves) & $1300 \mathrm{~m}$ & Calcareous & Small valley \\
\hline Puerto del Boyar .... & Cádiz & Nature park (Sierra de Grazalema) & $1100 \mathrm{~m}$ & Calcareous & Rocky slope facing south \\
\hline Sierra de Zafalgar .... & Cádiz & Nature reserve (Sierra de Grazalema) & $900 \mathrm{~m}$ & Calcareous & Small valley \\
\hline
\end{tabular}

filled and empty seeds. Filled seeds per cone ranged from zero to three, the modal value of the distribution being zero in every population except Punta Paloma, where it was unity (fig. 1). The mean number of filled seeds per cone varied between populations. That of Puerto del Boyar had the lowest value $(0.33$; table 2$)$ and presented, at most, one filled seed per cone (fig. 1). In contrast, the Punta Paloma population presented the highest mean number of filled seeds per cone (1.11; table 2).

Plants of each studied population displayed wide differences in seed viability. Thus, in Puerto del Boyar one individual had $0 \%$ seed viability while another reached $60 \%$. Among populations, the highest seed viability was found in Punta Paloma (mean 52.58\%) and the lowest were those of Puerto del Boyar and Punta Umbría (20.24\% and $20.26 \%$, respectively; table 2).

The proportions of male and female individuals did not differ from unity $(P>0.05)$ except in the Punta Umbría population, which had a very low proportion of male individuals $(\mathrm{M} / \mathrm{F}=0.4, P<0.05$; table 2$)$. Cone production was independent of sex ratio $(R=$ $0.3, P=0.55, n=6$ ) as were mean number of filled seed per cone $(R=0.248, P=0.635, n=6)$ and mean seed viability $(R=0.32, P=0.536, n=6)$.

\section{Intersubspecies Variation}

In Juniperus oxycedrus subspecies, the average percentage of mature seed cones was significantly higher in the subsp. oxycedrus $(\mathrm{F}=9.04, P<0.01$; table 3$)$, while the number of ovules per cone was significantly higher in subsp. macrocarpa than in the subsp. oxycedrus $(\mathrm{F}=16.96, P=0.0001,1 \mathrm{df}$; table 3$)$. Nevertheless, the number of seeds in a mature cone was not significantly different in the two subspecies (means of 2.3 and 1.97 in subsp. macrocarpa and subsp. oxycedrus, respectively). Likewise, the mean number of filled seeds per cone was similar among subspecies, so that the percentage of seed viability was also similar (table 3). In subspecies macrocarpa, about $47 \%$ of mature cones had zero filled seeds, and in subspecies $o x$ ycedrus this proportion reached $56 \%$ (fig. 2). The seedset (ovules that develop into filled seeds) was higher in subspecies oxycedrus (with $21.7 \%$ ) than in macrocarpa $(17.4 \%)$.

The presence of two embryos within one seed (polyembryony) was found on two occasions: the first in subsp. oxycedrus (Sierra de Zafalgar population) and the second in subsp. macrocarpa (Punta Paloma population).

\section{Discussion}

Mature cone production in Juniperus oxycedrus depends on the number of cones that develop after pollination. Because the time between pollination and fertilization is long, in this case ca. 6-7 mo (M. Arista et al., unpublished data), cone development is independent of ovule fertilization. In J. oxycedrus, pollination takes place in October-November. Seed cones are receptive during the whole pollination period, but unpollinated seed cones continue secreting pollen drops for several weeks, and receptivity may extend even until February. The bulk of seed cone abortion in this species took place during this stage, indicating that pollen is essential for seed cone development, as occurs in other conifers (Sarvas 1962; Dogra 1967; Owens and Blake 1984; Colangeli and Owens 1990). Thus, the percentage of mature cones reflects the de-

Table 2 Mature Cone Production (\%) and Seed Characters of Six Populations of Juniperus oxycedrus

\begin{tabular}{|c|c|c|c|c|c|c|c|c|c|c|}
\hline \multirow{2}{*}{$\begin{array}{c}\text { Subspecies and } \\
\text { population }\end{array}$} & \multicolumn{3}{|c|}{ Mature cone production $(\%)$} & \multicolumn{3}{|c|}{ Filled seeds } & \multicolumn{3}{|c|}{ Seed viability (\%) } & \multirow{2}{*}{$\begin{array}{l}\text { Sex } \\
\text { ratio }\end{array}$} \\
\hline & Mean $\pm \mathrm{SE}$ & Range & $n$ & Mean $\pm S E$ & Range & $n$ & Mean $\pm S E$ & Range & $n$ & \\
\hline \multicolumn{11}{|l|}{ macrocarpa: } \\
\hline Punta Umbría ........ & $19.23 \pm 4.14^{a}$ & $1.7-48.8$ & 14 & $0.60 \pm 0.09^{2}$ & $0.2-1.4$ & 13 & $20.26 \pm 2.91^{2}$ & $8-45.3$ & 13 & 0.4 \\
\hline Pinar de Barbate ... & $29.39 \pm 4.78^{\mathrm{bb}}$ & $0.7-46.6$ & 10 & $0.45 \pm 0.11^{2}$ & $0.1-1.3$ & 10 & $28.99 \pm 6.41^{\mathrm{b}}$ & $5.9-60$ & 10 & 1.16 \\
\hline Punta Paloma ........ & $38.32 \pm 4.01^{a b}$ & $29.8-49.1$ & 4 & $1.11 \pm 0.13^{b}$ & $0.1-1.5$ & 10 & $52.58 \pm 6.46^{b}$ & $6.4-72.2$ & 10 & 1 \\
\hline \multicolumn{11}{|c|}{ oxycedrus: } \\
\hline Puerto Saucillo ...... & $43.9 \pm 5.64^{b}$ & $15.5-71.4$ & 13 & $0.74 \pm 0.17^{\star b}$ & $0.05-1.6$ & 8 & $40.74 \pm 6.96^{b}$ & $2-66.6$ & 8 & 1.08 \\
\hline Puerto del Boyar ... & $28.69 \pm 3.45^{a b}$ & 7.9-39.6 & 10 & $0.33 \pm 0.13^{\circ}$ & 0-1 & 7 & $20.24 \pm 7.83^{\circ}$ & $0-60$ & 7 & 1.3 \\
\hline Sierra de Zafalgar .. & $39.86 \pm 3.72^{\mathrm{b}}$ & $26.7-64$ & 10 & $0.73 \pm 0.21^{\mathrm{b}}$ & $0.05-1.9$ & 7 & $29.99 \pm 7.79^{a b}$ & $2.4-70.3$ & 7 & 0.65 \\
\hline
\end{tabular}

Note. Entries sharing the same superscript do not differ significantly (Tukey test, $P<0.01$ ). Range refers to mean values per plant. 


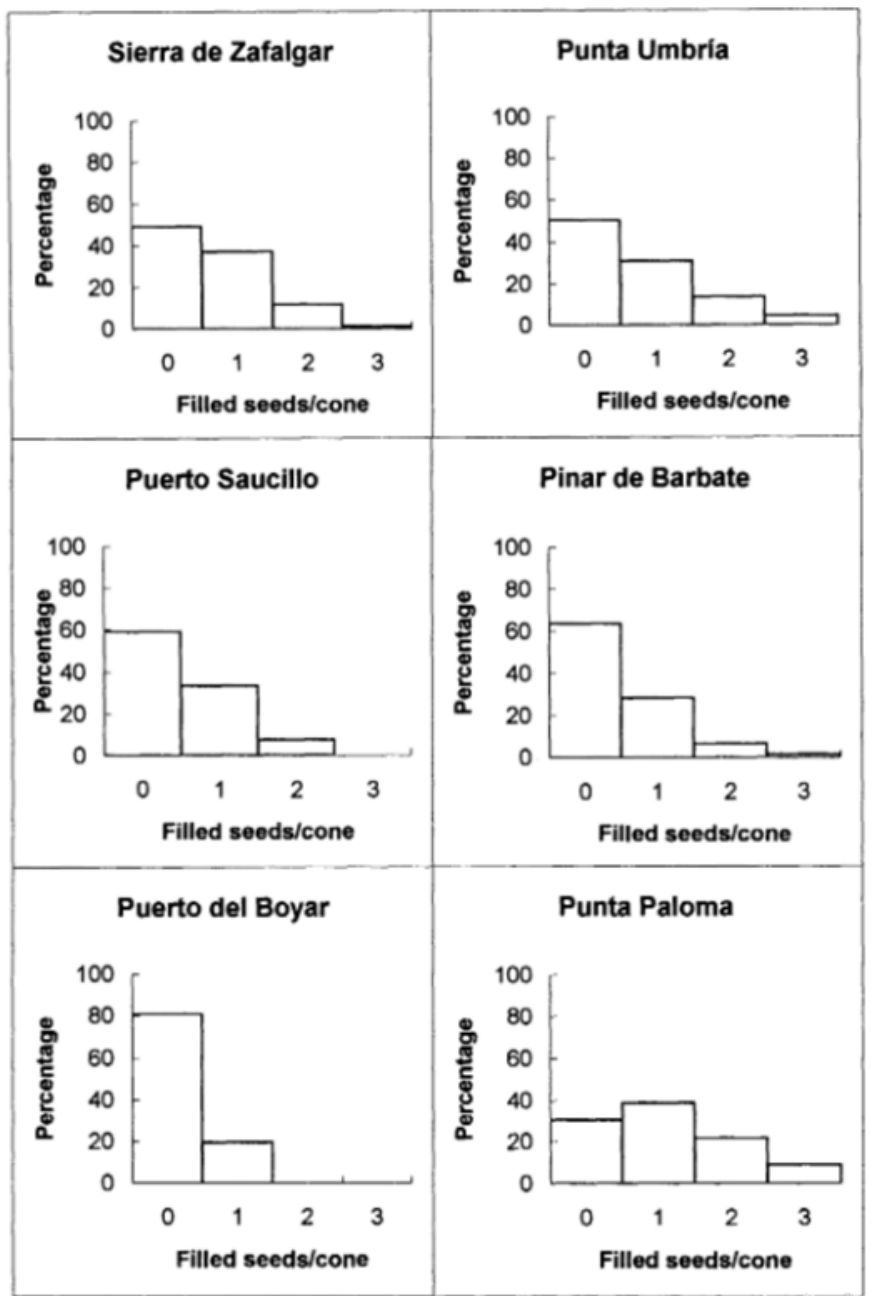

Fig. 1 Frequency distribution of the number of filled seeds per cone in six populations of Juniperus oxycedrus.

gree of pollination and differs markedly among individuals. In fact, pollen dispersal in wind-pollinated species is highly leptokurtic (Farris and Mitton 1984; Proctor et al. 1996); consequently, in dioecious species, large variances in reproductive success could result from proximity of mates (Freeman et al. 1997).

The proportion of aborted seed cones was quite high in all of the populations. The highest rate was found in Punta Umbría, where ca. $80 \%$ of seed cones aborted. This was the only population in which the sex ratio differed significantly from unity. The low proportion of male individuals, and consequently of pollen, could

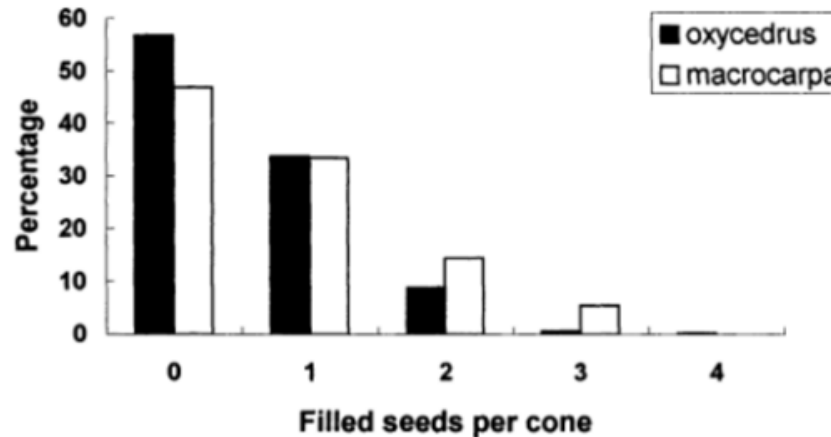

Fig. 2 Frequency distribution of the number of filled seeds per cone in Juniperus oxycedrus subsp. oxycedrus and in J. oxycedrus subsp. macrocarpa.

be the main cause of this abortion rate. However, the population of Puerto del Boyar presented the second highest rate of seed cone abortion and the highest sex ratio $(\mathrm{M} / \mathrm{F}=1.3)$. This population was situated on a calcareous rocky slope facing south, a site where summer drought was severe. In xeric sites, the greater cost associated with the production of fruits as opposed to pollen can give rise to a male-biased sex ratio in dioecious species (Freeman et al. 1976; Willson 1979). Moreover, in this population male and female individuals were clearly segregated by niches. Female individuals were distributed along a temporal watercourse that was probably the most favorable microsite. This kind of spatial segregation of sexes is common in dioecious wind-pollinated species (Bierzchudek and Eckart 1993; Freeman et al. 1997). In this situation, females could be pollen-limited in the more favorable microhabitats that they dominate (Freeman et al. 1993). This could be the reason of the low percentage of mature seed cones found in Puerto del Boyar population. Thus, spatial location of mates could be more important than sex ratio, if the latter is not extremely low.

In $J$. oxycedrus, the number of seeds per cone reflects the number of pollinated ovules (M. Arista et al., unpublished data). It is remarkable that the number of ovules per cone in J. oxycedrus, although different between subspecies, is lower than those in other Cupressaceae (Owens et al. 1990; Briand et al. 1992) and in most conifers. With only two to eight ovules, cones of $J$. oxycedrus would need only a few pollen grains to transform all their ovules into seeds. However, only some of these ovules were transformed into seeds, in-

Table 3 Characters of the Two Subspecies of Juniperus oxycedrus

\begin{tabular}{|c|c|c|c|c|c|c|}
\hline \multirow[b]{2}{*}{ Character } & \multicolumn{3}{|c|}{ macrocarpa } & \multicolumn{3}{|c|}{ oxycedrus } \\
\hline & Mean $\pm \mathrm{SE}$ & Range & $n$ & Mean $\pm \mathrm{SE}$ & Range & $n$ \\
\hline Mature cone production $(\%) \ldots \ldots$ & $25.59 \pm 2.98^{\circ}$ & $0.7-49.1$ & 28 & $38.07 \pm 2.86^{\circ}$ & 7.9-71.4 & 33 \\
\hline Ovules/cone...$\ldots \ldots \ldots \ldots \ldots \ldots \ldots \ldots \ldots \ldots \ldots \ldots$ & $4.1 \pm 0.25$ & 3-8 & 30 & $2.8 \pm 0.12^{\mathrm{b}}$ & $2-4$ & 30 \\
\hline Seeds/cone..$\ldots \ldots \ldots \ldots \ldots \ldots \ldots \ldots$ & $2.31 \pm 0.12^{a}$ & $1.0-3.3$ & 33 & $1.97 \pm 0.12^{a}$ & $1-2.8$ & 22 \\
\hline Filled seeds/cone $\ldots \ldots \ldots \ldots \ldots$ & $0.71 \pm 0.08^{a}$ & $0.1-1.5$ & 33 & $0.61 \pm 0.1^{2}$ & $0-1.9$ & 22 \\
\hline Seed viability $(\%)$.................... & $32.7 \pm 3.75^{a}$ & $5.9-72.2$ & 33 & $30.8 \pm 4.51^{\circ}$ & $0-70.3$ & 22 \\
\hline
\end{tabular}

Note. Range refers to mean values per plant. Entries sharing the same superscript do not differ significantly (ANOVA, $P<0.01$ ). 
dicating a deficient pollination. Pollination problems are usual in conifers (Owens and Molder 1977, 1979; Singh and Owens 1981; Colangeli and Owens 1990, 1991; Arista and Talavera 1994). Deficient pollination is more critical in the subspecies macrocarpa, because the two subspecies had a similar number of seeds per cone, but cones in subspecies macrocarpa had a higher number of ovules.

Of the seeds produced by J. oxycedrus, only ca. $31 \%$ had an embryo, leading to a similar mean number of 0.6 and 0.7 filled seeds per cone in subsp. oxycedrus and macrocarpa, respectively. In the dioecious Juniperus communis, the proportion of empty seeds is also markedly high, ranging from $40 \%$ to $96 \%$ in different populations (Houle and Babeux 1994). Owens et al. (1990) reported that if abortion takes place after fertilization period in Thuja plicata, the empty seeds would be externally indistinguishable from ripe filled seeds. This situation is similar to J. oxycedrus. Main causes of seed abortion at this stage are poor pollen viability or vigor (Owens et al. 1990), or endogamy (Sorensen 1982; Owens et al. 1991; Arista and Talavera 1996). As $J$. oxycedrus is a dioecious species, selfing is ruled out as a cause of abortion. Because of the nature of our work, it is not possible to know the effect of endogamy (crosses between siblings) and pollen vigor or viability as sources of empty seeds, but they should not be ruled out. The fact that the Puerto del Boyar population, situated in the most xeric site, showed the lowest number of filled seeds per cone indicates that resource limitation could be partly responsible for seed abortion at this stage. In fact, the investment in the maturing embryos may be very large (Willson 1983). Moreover, in J. oxycedrus the two reproductive cycles overlap, and two seed cone crops cooccur in an individual. Thus, female individuals re- quire an investment of considerable magnitude for reproduction. In consequence, if resources are limited, abortion of developing embryos is likely to occur in J. oxycedrus. Decrease in reproductive female success in xeric sites has been reported previously (Freeman and Vitale 1985), and xeric conditions are usual in the Mediterranean region where $J$. oxycedrus is distributed.

On the other hand, the distribution area of J. oxycedrus subsp. macrocarpa in southwestern Spain has decreased recently as the consequence of urbanistic pressures on the coast. As a result, this taxon has become vulnerable in the zone, and restoration programs have been set in motion. The results of our study have several implications for the production and collection of juniper seeds. It would be appropriate to collect seeds from female individuals that have a very close mate and are placed in favorable sites. Of the studied populations, Punta Paloma had the highest number of filled seeds per cone, and this population seems to be the most suitable for seed collection.

In conclusion, both subspecies of J. oxycedrus display high percentages of empty seeds per cone. Populations and plants differ in their seed viability, and thus preliminary screening is necessary to optimize seed production for restoration purposes. Moreover, dioecy makes this species more vulnerable to any management-altering sex ratio or mate distances.

\section{Acknowledgments}

We thank Drs. J. N. Owens and D. C. Freeman for their useful comments, which improved this manuscript. This research was supported by grant 4086 (Ayuda a los grupos de investigación) from the Junta de Andalucía and by the Parque Natural Sierra de Grazalema (Proyecto Pinsapar, A.M.A.).

\section{literuture Cited}

Arista M, S Talavera 1994 Pollen dispersal capacity and pollen viability of Abies pinsapo Boiss. Silvae Genet 43:155-158.

1996 Density effect on the fruit-set, seed crop viability and seedling vigour of Abies pinsapo. Ann Bot 77:187-192.

1997 Gender expression in Abies pinsapo Boiss., a Mediterranean fir. Ann Bot 79:337-342.

Bierzchudek P, V Eckart 1993 Spatial segregation of the sexes in dioecious plants. Am Nat 132:34-43.

Briand CH, U Posluszny, DW Larson 1992 Comparative seed morphology of Thuja occidentalis (eastern white cedar) from upland and lowland sites. Can J Bot 70:434-438.

Colangeli AM, JN Owens 1990 The relationship between time of pollination, pollination efficiency, and cone size in western red cedar (Thuja plicata). Can J Bot 68:439-443.

1991 Effects of accelerated pollen cone development on pollen cytology and fertilizing potential in western hemlock (Tsuga heterophylla). For Ecol Manag 40:151-162.

Dogra PD 1967 Seed sterility and disturbances in embryogeny in conifers with particular reference to seed testing and tree breeding in Pinaceae. Stud For Suec 45:1-97.

Farris M, JB Mitton 1984 Population density, outcrossing rates, and heterozygote superiority in Ponderosa pine. Evolution 38: $1151-1154$.

Franco JA 1964 Juniperus. Pages 38-39 in Tutin TG, VH Heywood, NA Burges, DH Valentine, SM Walters, DA Webb, eds. Flora Europaea. Vol 1. Cambridge University Press, Cambridge.
Freeman DC, LG Klikoff, KT Harper 1976 Differential resource utilization by the sexes of dioecious plants. Science 193:597-599.

Freeman DC, J Lovett Doust, A El-Keblawy, KJ Miglia, DE McArthur 1997 Sexual specialization and inbreeding avoidance in the evolution of dioecy. Bot Rev 31:65-92.

Freeman DC, ED McArthur, SC Sanderson, AR Tiedeman 1993 The influence of topography on male and female fitness components of Atriplex canescens. Oecologia 93:538-547.

Freeman DC, JJ Vitale 1985 The influence of environments on the sex ratio and fitness of spinach. Bot Gaz 146:137-142.

Houle G, P Babeux 1994 Variations in rooting ability of cuttings and in seed characteristics of five populations of Juniperus communis var. depressa from subarctic Quebec. Can J Bot 72:493498 .

Jordano P 1991 Gender variation and expression of monoecy in Juniperus phoenicea (L.) (Cupressaceae). Bot Gaz 152:476-485.

Kuittinen H, O Savolainen 1992 Picea omorika is a self-fertile but outcrossing conifer. Heredity 68:183-187.

Owens JN, MD Blake 1984 The pollination mechanism of sitka spruce (Picea sitchensis). Can J Bot 62:1136-1148.

Owens JN, AM Colangeli, SJ Morris 1990 The effect of self-, cross-, and no pollination on ovule, embryo, seed, and cone development in western red cedar (Thuja plicata). Can J For Res 20:66-75.

1991 Factors affecting seed set in Douglas fir (Pseudotsuga menziesii). Can J Bot 69:229-238. 
Owens JN, M Molder 1977 Sexual reproduction of Abies amabilis. Can J Bot 55:2653-2657.

1979 Sexual reproduction of Larix occidentalis. Can J Bot 57:2673-2690.

Proctor M, P Yeo, A Lack 1996 The natural history of pollination. Harper Collins, London.

Sarvas R 1962 Investigations on the flowering and seed crop of Pinus silvestris. Commun Inst For Fenn 53:1-192.

Singh H, JN Owens 1981 Sexual reproduction in subalpine fir (Abies lasiocarpa). Can J Bot 59:2650-2666.
Sokal RR, FJ Rohlf 1981 Biometry. 2d ed. Freeman, San Francisco.

Sorensen FC 1982 The roles of polyembryony and embryo viability in the genetic system of conifers. Evolution 36:725-733.

Willson MF 1979 Sexual selection in plants. Am Nat 113:777790.

1983 Plant reproductive ecology. Wiley, New York.

Wilson P, M Buonopane, TD Allison 1996 Reproductive biology of the monoecious clonal shrub Taxus canadiensis. Bull Torrey Bot Club 123:7-15. 